\title{
Current status and future prospects of Lhalu wetland on the Tibetan Plateau
}

\author{
Hui Wang, Dong Xie, Wen Xiong, Wei Tang, Zhigang Wu, Keyan Xiao \& Qiang Wang \\ Keywords: urban wetland, biodiversity conservation, human settlement, ecological restoration
}

\section{Abstract}

Lhalu wetland, located in the northwest of Lhasa city, Tibet, is the highest and largest urban natural wetland in the world. Due to its specific climate and the unique plateau ecosystem, it is a hotspot of endemic and endangered species. Lhalu wetland is an important wetland for Lhasa city for its biodiversity and for enhancing human well-being. However, due to global warming, over-exploitation and the presence of non-native species, it has suffered serious ecosystem damage and biodiversity loss. To protect biodiversity and the functioning of the ecosystem, new measures are needed, and current measures should be better enforced. This study is important for biodiversity conservation and the management of Lhalu wetland in the QinghaiTibet plateau.
Profile

Protected area

Lhalu wetland

Mountain range

Himalaya, China

\section{Introduction}

Wetland ecosystems cover only $1.5 \%$ of the Earth's surface, but provide about $40 \%$ of the value of all ecosystem services in the world (Zedler 2003). However, globally, wetland areas have decreased rapidly (Davidson 2014), notably in China, where the last thirty years have seen their massive reduction (Mao et al. 2018). The Qinghai-Tibet plateau has the most densely distributed wetland areas in China (Xu et al. 2019). However, some wetlands have experienced degradation caused by multiple factors (Meng et al. 2017). This has been the case for Lhalu wetland, which is the highest and largest urban natural wetland in the world (Chen et al. 2018), where degradation has been rapid. In this study, for better protection of highland wetlands generally, we provide an overview of the status, threats and conservation recommendations for Lhalu wetland.

\section{Study area}

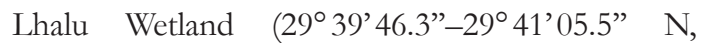
$91^{\circ} 03^{\prime} 48.5^{\prime \prime}-91^{\circ} 06^{\prime} 51.4^{\prime \prime} \mathrm{E}$; average elevation $3645 \mathrm{~m}$; total area $6.6 \mathrm{~km}^{2}$ ) is located in the northwest of Lhasa city, the capital of Tibet, China (Figure 1). It is a swampy wetland of peat and reeds, located in a temperate, semi-arid, monsoon climate zone in the southern Tibetan Plateau. The average annual precipitation is $439.8 \mathrm{~mm}$, and most rain falls between July and September. Temperatures are low, ranging from $16^{\circ} \mathrm{C}$ (extreme $30^{\circ} \mathrm{C}$ ) in June or July, to $-1.6^{\circ} \mathrm{C}$ (extreme $-16.5^{\circ} \mathrm{C}$ ) in January (average temperature $7.5^{\circ} \mathrm{C}$ ). The principal rivers are the Lhasa and the Liusha, which are fed mainly by rainwater and alpine snow-melt.

\section{Method}

We gathered biodiversity information from diverse sources, searching for the combination of words bio- diversity and Lhalu wetland in the Web of Science (ISI, http://www.isiknowledge.com) and the China National Knowledge Infrastructure (http://www.cnki.net). We also looked for biodiversity information in various Chinese publications, such as the Comprehensive investigation report on Lhalu wetland nature reserve (LEPA 2004). Threatened and endangered species were identified according to the red list categories of the International Union for Conservation of Nature (IUCN, www. iucnlist.org) and the China Species Red List (Wang \& Xie 2004).

\section{Biodiversity}

In terms of flora, previous surveys indicated the presence of 85 vascular plant species belonging to 30 families distributed in the marsh. At the family level, Gramineae were the most dominant, with 20 species, followed by Cyperaceae, with 13. Other families contributed fewer than five species each ( $\mathrm{Li}$ et al. 2008); some non-native species, such as Amaranthus tricolor and Oxalis corymbose, have invaded Lhalu wetland. The wetland supports rich and endemic animal resources: 62 bird species belonging to 24 families of 13 orders; 10 fish species belonging to 4 families of 3 orders; 4 amphibian species belonging to 2 families of 1 order; 255 species of protozoa belonging to 79 families of 5 orders. Seven bird species are identified as protected species in China, where there are two levels of protection. These are Grus nigricollis and Gypaetus barbatus (classified at the higher protection level), and Milvus korschun, Accipiter nisus, Buteo buteo, Falco peregrinus and Falco tinnunculus (classified at the second level of protection). Anser indicus and Tadorna ferruginea are listed as protected species in the Tibet Autonomous Region (Ba et al. 2009). 


\section{Current degradation status of Lhalu wet- land}

For a long time, Lhalu wetland was considered wasteland by local residents (Yeh 2009). The area of the wetland decreased sharply in the years 1950-2000 (Table 1). It then remained constant until 2005, thanks to the creation of the Lhalu National Nature Reserve. Although the total area of Lhalu wetland has not decreased any further in the last ten years, the wetland ecosystem has become degraded. Firstly, the water levels in the wetland continued to fall. In the 1950s, the wetland was entirely covered by standing water thanks to the continuous flow of the Liusha river throughout the year. Now, the proportion of water-covered area to total area has significantly decreased (Li 2005). Some areas of wetland ecosystem have converted to meadow and eventually to sandy land (Zhang et al. 2013). Secondly, the plant community structure, species composition and diversity of Lhalu wetland have changed dramatically in the past seventy years. The height of the grasses has decreased from $2 \mathrm{~m}$ to less than $1 \mathrm{~m}$ in the past seventy years, and the yield of grass fell from $12690 \mathrm{~kg}$ / ha in the $1960 \mathrm{~s}$ to $945 \mathrm{~kg}$ / ha in the 2000s, and now to $63 \mathrm{~kg} / \mathrm{ha}$ (Chen et al. 2018). Forty years ago, the typical vegetation was reed (Phragmites australis); in the 2000s, the area was dominated by Carex spp., Kobresia spp., and Juncus spp. (Laduo et al. 2009). The number of plant species increased significantly from 53 in 1985 (mostly hydrophytes, such as Hippuris vulgaris and Potamogeton distinctus) to 85 in 2008 (mostly mesophytes, such as species of Gramineae and Cyperaceae).

\section{Threats to Lhalu wetland}

\section{Global warming}

The Qinghai-Tibet Plateau is one of the most sensitive regions to global warming ( $\mathrm{Lu} \& \mathrm{Liu} 2010$ ). Over the past sixty years, the annual average temperature of Lhalu wetland has increased gradually (Tang et al. 2019). Especially since 1995, there have been significant increases in Lhasa city in the winter temperature and the annual average temperature (Zhao et al. 2015). The highest recorded summer temperature was in excess of $30^{\circ} \mathrm{C}$ in 2019 , far exceeding the hottest temperature record of $25^{\circ} \mathrm{C}$ in 2009 . Higher temperatures

Table 1 - Changes in the city (Lhasa) and Lhalu wetland areas in the past sixty years

\begin{tabular}{|c|c|c|}
\hline Year & $\begin{array}{l}\text { Area of Lhasa } \\
\left(\mathbf{k m}^{2}\right)\end{array}$ & $\begin{array}{l}\text { Area of Lhalu wetland } \\
\left(\mathrm{km}^{2}\right)\end{array}$ \\
\hline 1951 & 3.16 & 12 \\
\hline 1952-1959 & 4.26 & 11.2 \\
\hline 1960-1969 & 14.43 & 10.5 \\
\hline 1970-1979 & 21.90 & 10.5 \\
\hline $1981-1989$ & 43.40 & 9.6 \\
\hline $1990-2000$ & 54 & 6.2 \\
\hline $2001-2010$ & 62.88 & 6.6 \\
\hline $2011-2019$ & 77.9 & 6.6 \\
\hline
\end{tabular}

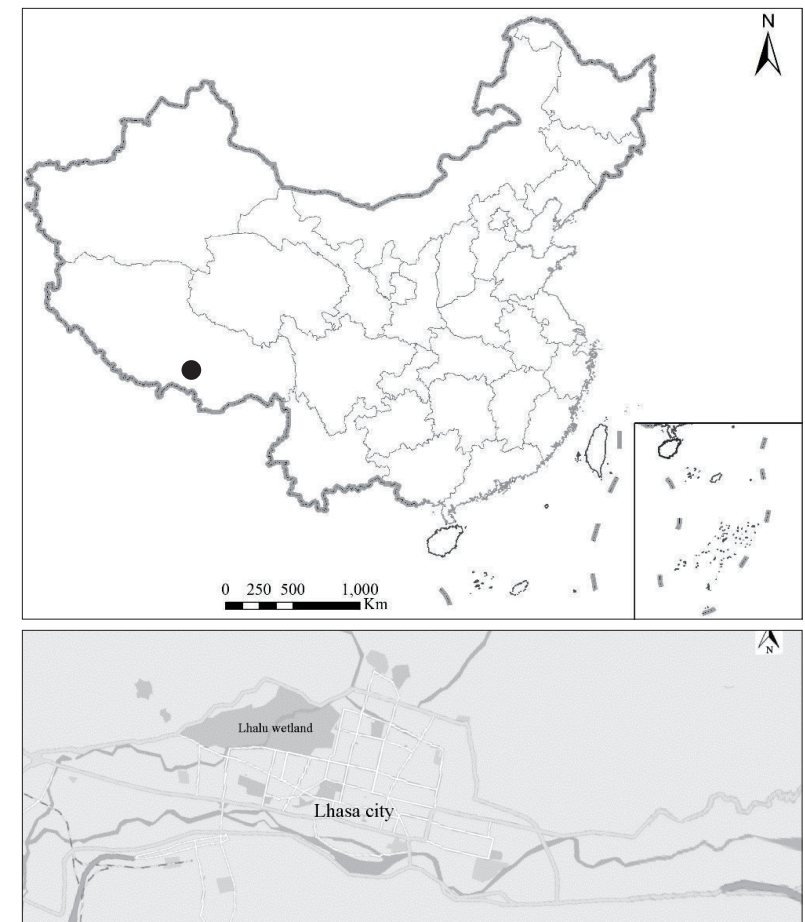

Figure 1 - Lhasa city and Lhalu wetland.

lead to increased evapotranspiration, and the water level of Lhalu wetland has generally been decreasing since the 1960s (Hua et al. 2007).

\section{Human disturbance}

Human disturbance is the most important cause of degradation of Lhalu wetland. Before the 1960s, the wetland supported high biodiversity, with dozens of different species per square kilometre. From 1964, drainage canals and roads were built in the wetland, and in the 1970s farms and infrastructure built around the wetland caused the peat gradually to degrade. In the mid-1980s, stones and gravel blocked the incoming water and quicksand from the Niangergou and Duodigou rivers, causing desertification in the north of the wetland at a rate of 1 to 1.5 acres per year. In the $1990 \mathrm{~s}$, the construction of the main canal greatly changed the hydrological conditions of the wetland. Because the canal can only be drained and not irrigated, $70 \%$ of the water in Lhalu wetland was discharged directly into the River Lhasa. In 2000, over 5000 farm animals were being raised in the wetland, at one point reaching 7000 , and more than 1000 farmers were cutting hay there. Finally, since 2000, a further large area of Lhalu wetland has become seriously desertified and natural vegetation has been reduced significantly (Zong et al. 2005).

Non-native species

Non-native species are one of the main threats for aquatic biodiversity (Mack et al. 2000). China is now the country with highest number of non-native aquatic species in the world, and consequently has suffered great ecological and economic damage (Xiong et al. 2015, 2017; Wang et al. 2016). Despite that, the num- 
ber of non-native species in Tibet is lower than in other administrative regions (Bai et al. 2013). Recently, many non-native aquatic species were introduced into the Qinghai-Tibet Plateau (Chen \& Chen 2010; Liu et al. 2015; Xiong et al. 2015; Sui et al. 2016). Some, such as Rana catesbeiana, Trachemys scripta elegans, Pseudorasbora parva, Carassius auratus, Misgurnus anguillicaudatus, Silurus asotus, Cyprinus carpio, Micropercops swinhonis and Paramisgurnus dabryanus, have established dense populations in Lhalu wetland, where the populations of many native species, such as Ptychobarbus dipogon, Schizopygopsis youngbusbandi and Triplophysa orientalis, have declined sharply due to the invasion of these non-native species (Liu et al. 2015).

\section{Measures and prospects for ecological res- toration}

Restoring hydrology and vegetation is the first priority in the ecological restoration of wetlands (Cui et al. 2009). In order to restore water levels in Lhalu wetland, the north canal was built in the 2000 s. Now, the north canal is the main water supply channel of the wetland, where the water remains $0.5-1.5 \mathrm{~m}$ deep throughout the year. The number of hydrophytes has recovered to 30 species, which are now found in $95 \%$ of the total area of wetland (figures for 2019). The restoration of the area's hydrology has benefited the restoration of the vegetation.

After the establishment of the Lhalu wetland $\mathrm{Na}$ tional Natural Reserve, human interference decreased greatly. In 2000, the Lhasa Municipal Government issued the Administrative Measures for the Lhalu Wetland Nature Reserve, compiled the General Plan for the Lalulu Wetland Nature Reserve, and established the Lhalu Wetland Reserve Management Station. In the 2000s, a fence of about $11 \mathrm{~km}$ long was constructed around the wetland. Thereafter, livestock grazing, peat exploitation, hunting and other human activities were banned in Lhalu wetland. Now, biodiversity in the wetland has rebounded sharply, with many endemic and protected species returning to the area.

Ecological monitoring is an important tool for the protection of endangered species and wetland restoration (Martin et al. 2007). Now, new technology and methods, such as remote sensing, automatic cameras and environmental DNA, are widely used for monitoring and protecting endangered species in the wetland (Klemas 2013). This ecological monitoring helps to improve the recovery of protected species, as well as to control the invasion of non-native species.

\section{Acknowledgements}

This research was supported by the Second Tibetan Plateau Scientific Expedition and Research programme (STEP), Grant No. 2019 QZKK0304, 2019 QZKK0501, and the National Natural Science Foundation of China (NO. 31600189 and 31900374). We are grateful to Professor Yifeng Chen, Dekui He, Dr Xiaoyun Sui, Yintao Jia, Xiu Feng and Ren Zhu who provided help in field investigation and valuable suggestions to improve this study. We are also grateful to the anonymous referees for their helpful comments on earlier versions of this paper.

\section{References}

Bai, F., R. Chisholm, W.G. Sang \& M. Dong 2013. Spatial risk assessment of alien invasive plants in China. Environmental Science \& Technology 47(14): 7624-7632.

Chen, T., W. Lang, E. Chan \& C.H. Philipp 2018. Lhasa: urbanising China in the frontier regions. Cities 74: 343-353.

Cui, B., Q. Yang, Z. Yang \& K. Zhang 2009. Evaluating the ecological performance of wetland restoration in the Yellow River Delta, China. Ecological Engineering 35: 1090-1103.

Davidson, N.C. 2014. How much wetland has the world lost? Long-term and recent trends in global wetland area. Marine and Freshwater Research 65(10): 934-941.

Hua, G.C., C.Y. Huang, Y.L. Li \& Y.-Z. Zhang 2007. Ecological protection and restoration of lalu wetland in Lasa city. Water Resources Protection 23(7): 93-96. In Chinese]

Klemas, V. 2013. Using Remote Sensing to Select and Monitor Wetland Restoration Sites: An Overview. Journal of Coastal Research 29(4): 958-970.

Laduo, B. J. \& P. Basang 2009. The relationship between composition and distribution of vegetation and environmental factors in Lhalu Dhamra, Lhasa. Journal of Tibet University (Natural Science Edition) 24(1): 15-20. [n Chinese]

LEPA (Lhasa Environmental Protection Agency). 2004. Comprehensive investigation report on Lhalu wetland nature reserve. Lhasa.

$\mathrm{Li}, \mathrm{C} .2005$. Research on the variation characteristics of eco-environment and propagation resources in Lalu wetland. Journal of Natural Resources 20(1): 145-151. In Chinese]

Li, C., K.S. Zhou, \& H. Li 2008. Species diversity and structure of main plant communities in Lalu wetland. Acta Botanica Boreali- Occidentalia Sinica 28(12): 2514-2520. [In Chinese]

Liu, C.L., Y.F Chen, J.D. Olden \& H. Dekui 2015. Phenotypic shifts in life history traits influence invasion success of goldfish in the Yarlung Tsangpo River, Tibet. Transactions of the American Fisheries Society 144(3): 602-609.

Lu, H. \& G. Liu 2010. Trends in temperature and precipitation of Tibetan Plateau, 1961-2015. Climate Research 43: 179-190.

Mack, R.N., D. Simberloff, W.M. Lonsdale, H. Evans, M. Clout \& F.A. Bazzaz 2000. Biotic invasions: causes, epidemiology, global consequences, and control. Ecological Application 10: 689-710.

Mao, D.H., Z.M. Wang, J.G. Wu, B.F. Wu, Y. Zeng, K.S. Song, K.P. Yi \& L. Luo 2018. China's wetlands 
loss to urban expansion. Land Degradation and Development 29: 2644-2657.

Martin, J., W.M. Kitchens \& J.E. Hines 2007. Importance of well-designed monitoring programs for the conservation of endangered species: Case study of the snail kite. Conservation Biology 21: 472-481.

Meng, W.Q., M.X. He, B.B. Hu, X.Q. Mo, H.Y. Li, B.Q. Liu \& Z.L. Wang 2017. Status of wetlands in China: A review of extent, degradation, issues and recommendations for improvement. Ocean \& Coastal Management 146: 50-59.

Sui, X.Y., X.A. Zhang, Y.T. Jia, Y. Chen \& D. Hui 2016. Predicting fish invasions in the Yarlung zangbo River of the Qinghai-Tibet Plateau, China. American Fisheries Society Symposium 84: 139-167.

Tang, B., G.B. Xiao \& L. Wu 2019. Variation characteristics of air temperature in Lhasa city in recent 54 years. Journal of Chengdu University of Information Technology 34(1): 72-76. [In Chinese]

Wang, H., Q. Wang, P.A. Bowler \& W. Xiong 2016. Invasive aquatic plants in China. Aquatic Invasions 11(1): 1-9.

Wang, S. \& Y. Xie. 2004. China Species Red List (Volume 1): Red List. Higher Education Press, Beijing.

Xiong, W., C.Y. Shen, Z.X. Wu, H. S. Lu \& Y.R. Yan 2017. A brief overview of known introductions of non-native marine and coastal species into China. Aquatic Invasions 12(1): 109-115.

Xiong, W., X.Y. Sui, S.H. Liang \& Y. Chen 2015. Non-native freshwater fish species in China. Reviews in Fish Biology and Fisheries 25: 651-687.

Xu, W.H., X.Y. Fan, J.G. Ma, S.L. Pimm, L.Q. Kong, Y. Zeng, X.S. Li, Y. Xiao, H. Zheng, J.G. Liu, B.F. Wu, L. An, L. Zhang, X.K. Wang \& Z.Y. Ouyang 2019. Hidden loss of wetlands in China. Current Biology 29: 3065-3071.

Zedler, J. 2003. Wetlands at your service: reducing impacts of agriculture at the watershed scale. Frontiers in Ecology and the Environment 1(2): 65-72.

Zhang, C., X.X. Zhang, G. Zhu \& F. Liu 2013. Lalu wetland area change trend and cause of formation analysis. Water Conservancy Science and Technology and Economy 19(2): 35-36. [In Chinese]

Zhao, J.B., X.X. Wang \& X.F. Zhang 2015. Characteristics of temperature changes in Lhasa from year 1980 to 2012 and its environmental significance. Journal of Tibet University 30(2): 33-39. [In Chinese]

Zong, H., C.S. Wang, C.Y. Huang et al. 2005. Research on ecological characteristics and ecological degradation of Tibetan Lhalu wetland. Journal of Southwest University for Nationalities (Natural Science Edition) 31(1): 72-78. [In Chinese]

\section{Authors}

Wang Hui ${ }^{1}$

is a lecturer in Forestry at Huazhong Agricultural University. She has a PhD in Ecology from Wuhan
University. Her research interests relate to biological conservation in forest ecosystems. E-mail: wanghui@ mail.hzau.edu.cn

\section{Xie Dong ${ }^{2}$}

is an associate professor at Nanjing Forestry University. He has a PhD in Ecology. His research interests relate to biological conservation in wetland ecosystems. E-mail: xiedong0123@gmail.com

\section{Xiong Wen ${ }^{3 *}$}

is a lecturer at Guangdong Ocean University. He has a $\mathrm{PhD}$ in botany. His research focuses on biological invasion and biodiversity conservation in vulnerable habitats. E-mail: chinaxiongwen@gmail.com

\section{Tang $\mathrm{Wei}^{4^{*}}$}

is a Senior Engineer at the Institute of Hydrobiology, Chinese Academy of Sciences. He has a Master's degree. His research focuses on the conservation of water resources. E-mail: tangwei@ihb.ac.cn

\section{Wu Zhigang ${ }^{4}$}

is a Research Associate Professor at the Institute of Hydrobiology, Chinese Academy of Sciences. He has a $\mathrm{PhD}$ in Ecology. His research focuses on plant ecology, evolution and systematics. E-mail: wuzg@ ihb.ac.cn

\section{Xiao Keyan ${ }^{5}$}

is a director at Hubei Xiuhu Botanical Garden. He has a $\mathrm{PhD}$ in Botany. His research focuses on the conservation of plant biodiversity. E-mail: xiaoky@whu. edu.cn

\section{Wang Qiang ${ }^{6}$}

is a Senior Engineer at East China Normal University. He has a PhD in Botany. His research focuses on the conservation of water resources. E-mail: wangqflora@163.com

${ }^{1}$ College of Horticulture \& Forestry Sciences / Hubei Engineering Technology Research Center for Forestry Information, Huazhong Agriculture University, Wuhan 430070, China

${ }^{2}$ Co-Innovation Center for Sustainable Forestry in Southern China, Nanjing Forestry University, Nanjing 210037, China

${ }^{3}$ College of Fisheries, Guangdong Ocean University, Zhanjiang 524088, China

${ }^{4}$ Institute of Hydrobiology, Chinese Academy of Sciences, Wuhan 430072, China

${ }^{5}$ Hubei Xiuhu Botanical Garden, Wuhan 430070, China

${ }^{6}$ Shanghai Key Laboratory for Urban Ecological Processes and Eco-Restoration, School of Ecological and Environmental Sciences, East China Normal University, Shanghai 200062, China 